\title{
SGLT1 in pancreatic $\alpha$ cells regulates glucagon secretion in mice, possibly explaining the distinct effects of SGLT2 inhibitors on plasma glucagon levels
}

\author{
Takayoshi Suga ${ }^{1,2}$, Osamu Kikuchi ${ }^{1}$, Masaki Kobayashi ${ }^{1}$, Sho Matsui ${ }^{1}$, Hiromi Yokota-Hashimoto ${ }^{1}$, \\ Eri Wada ${ }^{1}$, Daisuke Kohno ${ }^{1}$, Tsutomu Sasaki ${ }^{1}$, Kazusane Takeuchi ${ }^{3}$, Satoru Kakizaki ${ }^{2}$, Masanobu Yamada ${ }^{2}$, \\ Tadahiro Kitamura ${ }^{1, *}$
}

\section{ABSTRACT}

Objectives: It is controversial whether sodium glucose transporter (SGLT) 2 inhibitors increase glucagon secretion via direct inhibition of SGLT2 in pancreatic $\alpha$ cells. The role of SGLT1 in $\alpha$ cells is also unclear. We aimed to elucidate these points that are important not only for basic research but also for clinical insight.

Methods: Plasma glucagon levels were assessed in the high-fat, high-sucrose diet (HFHSD) fed C57BL/6J mice treated with dapagliflozin or canagliflozin. RT-PCR, RNA sequence, and immunohistochemistry were conducted to test the expression of SGLT1 and SGLT2 in $\alpha$ cells. We also used $\alpha \mathrm{TC1}$ cells and mouse islets to investigate the molecular mechanism by which SGLT1 modulates glucagon secretion.

Results: Dapagliflozin, but not canagliflozin, increased plasma glucagon levels in HFHSD fed mice. SGLT1 and glucose transporter 1 (GLUT1), but not SGLT2, were expressed in $\alpha$ TC1 cells, mouse islets and human islets. A glucose clamp study revealed that the plasma glucagon increase associated with dapagliflozin could be explained as a response to acute declines in blood glucose. Canagliflozin suppressed glucagon secretion by inhibiting SGLT1 in $\alpha$ cells; consequently, plasma glucagon did not increase with canagliflozin, even though blood glucose declined. SGLT1 effect on glucagon secretion depended on glucose transport, but not glucose metabolism. Islets from HFHSD and $d b / d b$ mice displayed higher SGLT1 mRNA levels and lower GLUT1 mRNA levels than the islets from control mice. These expression levels were associated with higher glucagon secretion. Furthermore, SGLT1 inhibitor and siRNA against SGLT1 suppressed glucagon secretion in isolated islets.

Conclusions: These data suggested that a novel mechanism regulated glucagon secretion through SGLT1 in $\alpha$ cells. This finding possibly explained the distinct effects of dapagliflozin and canagliflozin on plasma glucagon levels in mice.

(c) 2018 The Authors. Published by Elsevier GmbH. This is an open access article under the CC BY-NC-ND license (http://creativecommons.org/licenses/by-nc-nd/4.0/).

Keywords Alpha cell; Diabetes; Sodium glucose cotransporter; SGLT; Phloretin; Sotagliflozin

\section{INTRODUCTION}

Pancreatic $\alpha$ cells secrete glucagon, which controls blood glucose levels. In patients with type 1 or type 2 diabetes mellitus, hyperglycemia is often associated with hyperglucagonemia [1]. High levels of glucagon have been shown to contribute to diabetic hyperglycemia $[2,3]$. Thus, suppressing glucagon secretion could be a novel strategy for treating diabetes $[4,5]$. However, the mechanism underlying impaired glucagon secretion is not fully understood. Glucose is known to be a direct regulator of glucagon secretion [6-8]. Glucose uptake into $\alpha$ cells was previously thought to be controlled solely by the passive glucose transporter GLUT1 [9]; however, a recent report described the expression of sodium glucose cotransporters 1 and 2 (SGLT1 and SGLT2) in $\alpha$ cells [10]. SGLT1 and SGLT2 are active glucose transporters; they take up glucose against a concentration gradient through energy derived from sodium gradients [11]. In the kidney, these transporters are responsible for glucose reabsorption. Previously, SGLT2 was thought to be specifically expressed in the kidney; SGLT2 inhibitors were approved as clinical therapeutic agents for diabetes, because they promote urinary glucose excretion. Importantly, in clinical trials, when patients with type 2 diabetes were treated with selective SGLT2 inhibitors, such as dapagliflozin and

\footnotetext{
${ }^{1}$ Metabolic Signal Research Center, Institute for Molecular and Cellular Regulation, Gunma University, Maebashi, Gunma, Japan ${ }^{2}$ Department of Medicine and Molecular Science, Gunma University Graduate School of Medicine, Maebashi, Gunma, Japan ${ }^{3}$ Cosmic Corporation Co., Ltd., Bunkyo-ku, Tokyo, Japan

*Corresponding author. Metabolic Signal Research Center, Institute for Molecular and Cellular Regulation, Gunma University, 3-39-15 Showa-machi, Maebashi, Gunma, 371-8512, Japan. Fax: +81272 20 8849. E-mail: kitamura@gunma-u.ac.jp (T. Kitamura).

Abbreviations: $\alpha \mathrm{MG}$, methyl- $\alpha$-D-glucopyranoside; $\left[\mathrm{Ca}^{2+}\right]_{\mathrm{i}}$, intracellular calcium concentration; GIR, glucose infusion rate; GLP-1, glucagon-like peptide-1; HFHSD, high-fat, high-sucrose diet; $\mathrm{IC}_{50}$, half maximal $(50 \%)$ inhibitory concentration; NC, normal chow; SGLT, sodium glucose cotransporter; siRNA, small interfering RNA; T2DM, type 2
} diabetes mellitus 
empagliflozin, plasma glucagon levels increased, which enhanced hepatic glucose production $[12,13]$. It remains controversial whether these results were caused by a direct inhibition of SGLT2 in $\alpha$ cells or by a compensative mechanism triggered by declining blood glucose levels [12,14-16]. Bonner et al. reported that SGLT2 was expressed in $\alpha$ cells, and dapagliflozin increased plasma glucagon levels by inhibiting SGLT2 in $\alpha$ cells [10]. Conversely, a recent report showed that SGLT2 expression levels were nearly undetectable in $\alpha \mathrm{TC1}$ cells [17]. Also, perfused islets isolated from SGLT2-knockout mice did not differ from control islets in glucagon secretion under high or low glucose conditions [18]. Moreover, another SGLT2 inhibitor, canagliflozin, was reported to have no effect on plasma glucagon levels in diabetic rats [19].

On the other hand, SGLT1 is expressed in the small intestine and kidneys. This transporter is known to be associated with GLP-1 secretion [20-24]. SGLT1 in the ventromedial hypothalamus was also reported to play a significant role in sensing low plasma glucose [25].

Based on those findings, we hypothesized that SGLT1 in $\alpha$ cells might be associated with the regulation of glucagon secretion. In addition, we reasoned that the actions of SGLT2 inhibitors on SGLT1 might explain their different effects on glucagon. Compared to dapagliflozin, which is a specific SGLT2 inhibitor, canagliflozin could also inhibit SGLT1, although its potency for SGLT1 is much lower than its potency for SGLT2 [26]. Thus, we expected that canagliflozin might affect glucagon secretion differently from other highly specific SGLT2 inhibitors. The present study aimed to investigate these hypotheses.

For the past several decades, glucagon research has been hindered by the lack of specific, sensitive assay systems. In fact, Bak et al. reported that, of eight different commonly used glucagon assay kits, none provided sufficiently sensitive and specific measurements [27]. Therefore, we recently developed a novel, accurate analytical method for measuring glucagon using liquid chromatography and mass spectrometry (LC-MS/MS). In comparing glucagon levels detected with various assays against measurements with LC-MS/MS, we revealed that the Mercodia sandwich ELISA was much more accurate than the conventional RIA kits [28]. Most previous evaluations of the effects of SGLT2 inhibitors on plasma glucagon levels were conducted with conventional RIA kits $[12,13,19]$. Therefore, in the present study, we investigated the effects of SGLT2 inhibitors using Mercodia sandwich ELISA.

\section{MATERIAL AND METHODS}

\subsection{Animal studies}

All experimental procedures were performed according to the Guide for the Care and Use of Laboratory Animals, of the Science Council of Japan. The study was approved by the Animal Experiment Committee of Gunma University. All animals were maintained in a specific pathogen-free space under a 12-h light/dark regimen. We purchased 7-week old C57BL/6J male mice and diabetic $(d b / d b)$ male mice (Charles River Laboratories, Japan). C57BL/6J mice were randomly assigned to consume normal chow (CE-2, CLEA, Japan) or a high-fat, high-sucrose diet (HFHSD) containing 20\% sucrose, at the age of 8weeks. The total energy in the HFHSD (Oriental Yeast, Japan) consisted of protein $(17.2 \%)$, fat $(54.5 \%)$, and carbohydrate $(28.3 \%)$. Water was provided ad libitum. None of the animals included in the data analyses displayed any health impairments.

SGLT2 inhibitors were suspended in a $0.5 \%$ methyl cellulose solution (Wako, Japan). Food was removed from the cages before drug administration. At time $=0 \mathrm{~min}$, dapagliflozin (3 and $10 \mathrm{mg} / \mathrm{kg}$; Cayman Chemical Company, USA), canagliflozin (10 and $30 \mathrm{mg} / \mathrm{kg}$;
Mitsubishi Tanabe Pharma Corporation, Japan), or vehicle was administered orally to the animals via a stomach tube, at a volume of $10 \mu \mathrm{l} / \mathrm{g}$. Glucose levels of all the blood samples were measured with a glucometer (Sanwa Kagaku, Japan). Plasma glucagon, insulin, and active GLP-1 levels were measured using blood samples obtained at $\mathrm{t}=4 \mathrm{~h}$ with a Glucagon sandwich ELISA (Mercodia, Sweden), an insulin ELISA (Shibayagi, Japan), and an active GLP-1 ELISA (Shibayagi, Japan), respectively. Urine was collected in metabolic cages over a $4 \mathrm{~h}$ period after drug administration. Urine glucose was analyzed with a Glucose C II Test (Wako, Japan).

\subsection{Glucose clamp study}

C57BL/6J mice fed HFHSD (20-week old males) underwent aseptic surgery 1 week before the clamp studies. Mice were catheterized at the left common carotid artery and the right jugular vein. Clamps were performed on unrestrained, conscious mice. Food was removed at the start of drug administration. The glucose clamp was initiated at $\mathrm{t}=30 \mathrm{~min}$. Blood glucose levels were maintained at $8.3-13.8 \mathrm{mmol} /$ $\mathrm{L}$ during the 210 min clamps, by monitoring blood glucose every $10 \mathrm{~min}$ and infusing $40 \%$ dextrose, when necessary. Mice that received vehicle were infused with saline (controls). The glucose infusion rate (GIR) was expressed in $\mathrm{mmol} \mathrm{kg} \mathrm{BW}^{-1} \mathrm{~min}^{-1}$. Blood samples were collected at the end of the study to determine plasma glucagon.

\section{3. aTC1 cells and mouse islets}

aTC1 clone 6 cells (CRL-2934, ATCC, USA) were cultured in D-MEM medium supplemented with $10 \%$ FBS, $1 \%$ penicillin/streptomycin, $15 \mathrm{mM}$ HEPES, $0.1 \mathrm{mM}$ non-essential amino acids, and $16.7 \mathrm{mM}$ glucose, in a humidified atmosphere, containing $5 \% \mathrm{CO}_{2}$ as described $[7,10,17]$. Mouse islets were isolated as described [29]. Briefly, mice were anesthetized and killed by cervical dislocation. Islets were purified from mice with collagenase (C7657, Sigma, Japan) digestion and subsequent centrifugation over a Histopaque gradient.

\subsection{RT-PCR, quantitative PCR, and high-throughput RNA-} sequencing

Total RNA was isolated from $\alpha \mathrm{TC} 1$ cells, mouse islets, and mouse kidneys with the RNAiso Plus kit (Takara, Japan). Isolated RNA was reverse transcribed to cDNA with the Improm II Reverse Transcription System (Promega, Japan). cDNA samples $(1 \mu \mathrm{g})$ were subjected to RTPCR, with a PCR Kit (TaKaRa, Japan), or quantitative PCR (qPCR), with the Applied Biosystems ViiA 7 Real-Time PCR System (Life Technologies, Japan) and the PowerUp ${ }^{\mathrm{TM}}$ SYBR $^{\mathrm{TM}}$ Green Master Mix (Fisher Scientific, USA). The specific primer sequences were listed in Supplementary Table 1. Target mRNA expression levels were evaluated relative to mouse $\beta$-actin mRNA levels (control gene). Highthroughput RNA sequencing was performed by DNA Chip Research, Inc., Tokyo, Japan.

\subsection{Immunohistochemistry}

C57BL/6J mice fed HFHSD (22-week old males) were anesthetized and perfused transcardially with ice-cold, $0.05 \mathrm{M}$ phosphate-buffered saline (pH 7.4), followed by $4 \%$ paraformaldehyde (PFA) for fixation. The pancreas and kidney were dissected and fixed in $4 \%$ PFA at $4{ }^{\circ} \mathrm{C}$. Samples were frozen in OCT compound and sectioned in $5-\mu \mathrm{m}$ thick slices. Human tissue sections were purchased (BioChain Institute Inc., USA). For immunostaining, we used rabbit polyclonal anti-SGLT1 (ab14685; abcam, Japan), rabbit polyclonal anti-SGLT2 (ab85626; abcam, Japan), guinea pig polyclonal anti-insulin (A0564; Dako, Japan), and mouse monoclonal anti-glucagon (ab10988; abcam, 
Japan) antibodies. We visualized immune complexes with FITC- or CY3-conjugated secondary antibodies.

\section{6. siRNA transfection}

For siRNA-silencing experiments, mouse islets and $\alpha \mathrm{TC} 1$ cells were transfected with scrambled control or the mouse Slc5a1 Silencer Select siRNA (s73953, Ambion, Life Technologies, Japan). Transfections were performed with Lipofectamine RNAiMAX (13778, Invitrogen Life Technologies, Japan). The knock-down efficiency was evaluated at $48 \mathrm{~h}$ after transfection with a quantitative RT-PCR analysis. At $96 \mathrm{~h}$ after transfection, cells were transferred to new plates for secretion experiments.

\subsection{Glucagon secretion experiment}

Ten size-matched mouse islets or $\alpha \mathrm{TC} 1$ cells were treated with or without various concentrations of dapagliflozin, canagliflozin, sotagliflozin (Chemscene, USA), or phloretin (Wako, Japan). The glucose concentration was $5 \mathrm{mM}$, unless otherwise stated. Supernatants were assayed for glucagon with the sandwich ELISA. Results were normalized to total protein levels. High methyl- $\alpha$-D-glucopyranoside $(\alpha M G)$ condition $(100 \mathrm{mM})$ was experimented as previously described $[20,21]$. Osmolarity was maintained in experiments with high $\alpha M G$ by reducing the $\mathrm{NaCl}$ concentration to $95 \mathrm{mM}$. Control solutions for these experiments contained $100 \mathrm{mM}$ mannitol.

\subsection{Calcium imaging}

Intracellular calcium concentration $\left[\mathrm{Ca}^{2+}\right]_{\mathrm{i}}$ was measured by ratiometric fura-2 fluorescence imaging, as previous described $[21,30]$.

\subsection{Statistical analysis}

Data are presented as the mean $\pm \mathrm{SE}$. The significance of differences was assessed with the Student's $t$-test or ANOVA followed by post hoc tests (Dunnett's or Tukey-Kramer's test) for multiple comparisons. $p$ values $<0.05$ were considered statistically significant.
A

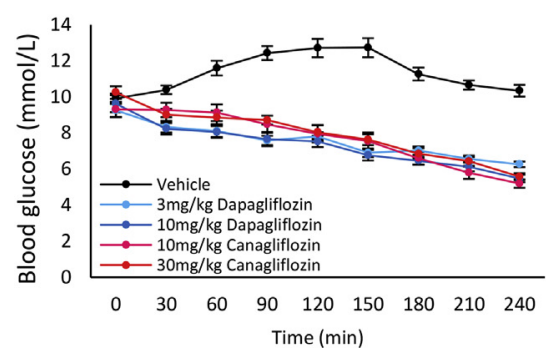

C

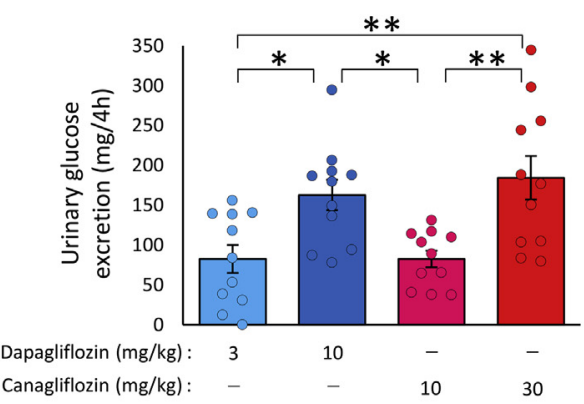

E

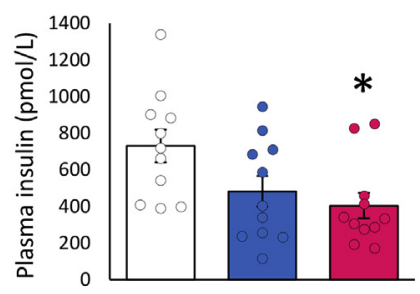

Dapagliflozin $(\mathrm{mg} / \mathrm{kg})$ :

Canagliflozin $(\mathrm{mg} / \mathrm{kg})$ :
10

10
B

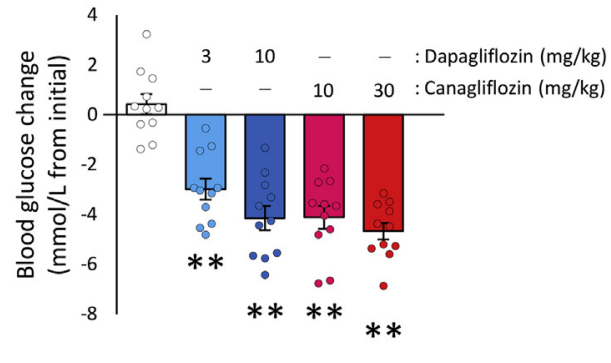

D

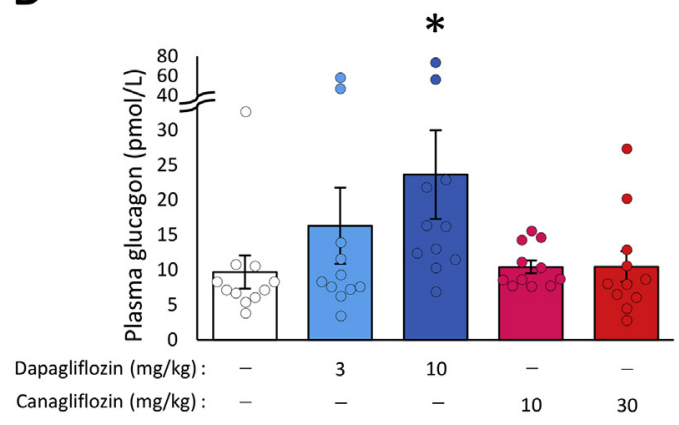

$\mathbf{F}$

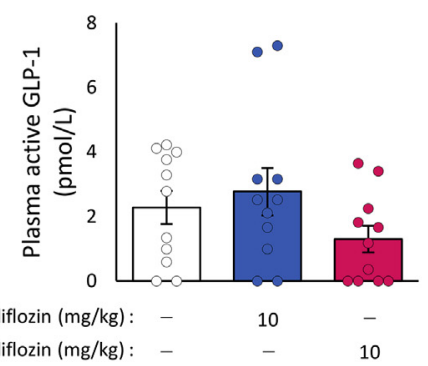

Figure 1: Plasma glucagon levels were increased with dapagliflozin and unaltered with canagliflozin in HFHSD fed mice. (A) Time course of blood glucose levels and (B) the changes in blood glucose at $4 \mathrm{~h}$ after administration of the indicated doses of vehicle, dapagliflozin, or canagliflozin in HFHSD mice, at 20 -weeks of age. ( $\mathrm{n}=11$ ). (C) Urinary glucose excretion in HFHSD mice collected at $4 \mathrm{~h}$ after treatment with the indicated doses of dapagliflozin or canagliflozin. ( $\mathrm{n}=11)$. (D) Plasma glucagon, (E) insulin, and (F) active GLP-1 levels in HFHSD mice treated with the indicated doses of vehicle, dapagliflozin, or canagliflozin. $(\mathrm{n}=11)$. Data are the mean $\pm \mathrm{SE}{ }^{*} p<0.05,{ }^{* \star} p<0.01$; vs. vehicle group or between the indicated groups. 


\section{RESULTS}

3.1. Dapagliflozin, but not canagliflozin, increased plasma glucagon in HFHSD mice

Dapagliflozin and empagliflozin were reported to increase plasma glucagon levels in patients with type 2 diabetes [12,13]; in contrast, canagliflozin did not alter plasma glucagon levels in rats [19]. However, in those studies glucagon was measured with conventional RIA kits, which are unreliable. Therefore, we first tested the effects of dapagliflozin and canagliflozin on plasma glucagon levels in HFHSD mice with the sandwich ELISA system, which we had recently confirmed was more accurate than the conventional RIA for glucagon
A

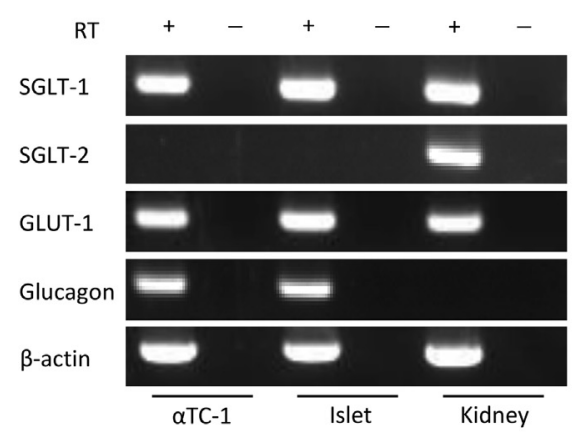

B

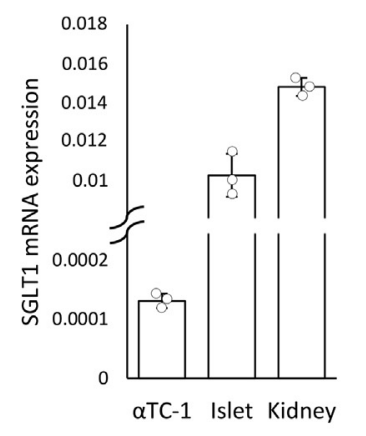

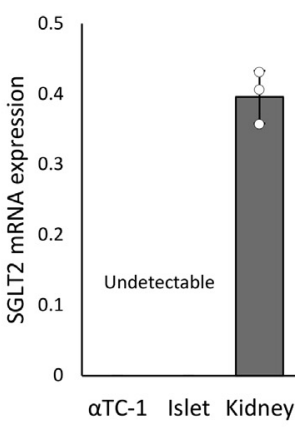

C

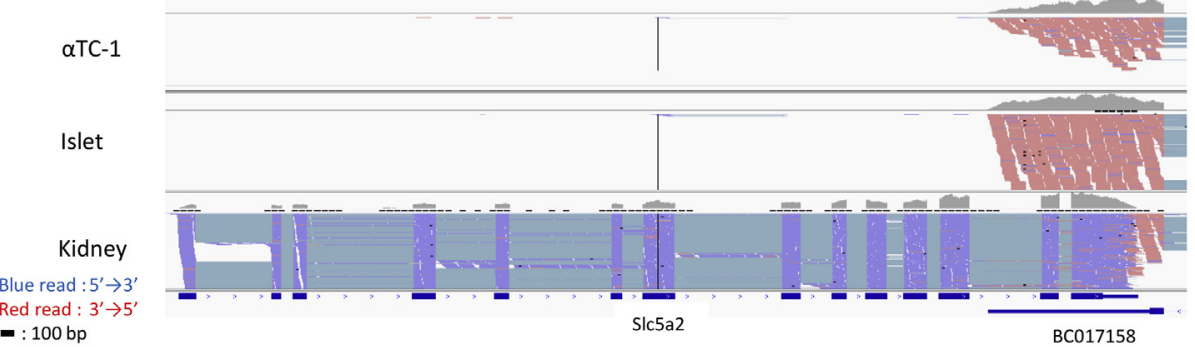

D

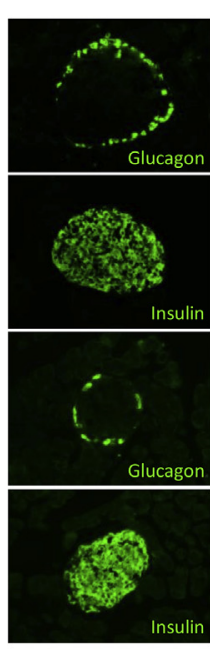

Mouse pancreas
E

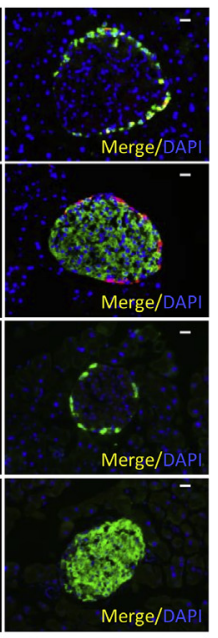

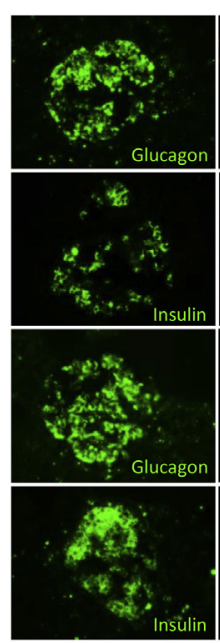

Human pancreas
$\mathbf{F}$

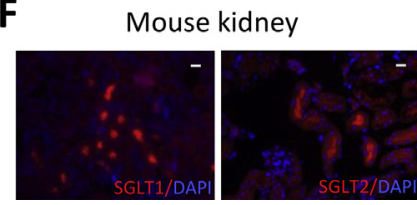

G

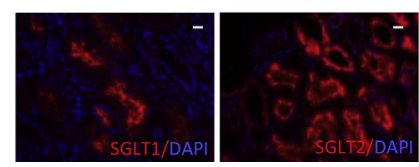

Figure 2: SGLT1, but not SGLT2, is expressed in $\alpha \mathrm{TC1}$ cells, mouse islets, and human islets. (A) RT-PCR analyses for SGLT1, SGLT2, GLUT1, glucagon, and $\beta$-actin expression, in $\alpha$ TC1 cells, mouse islets, and mouse kidney. (B) Quantitative real-time RT-PCR analyses for SGLT1 and SGLT2 expression, relative to $\beta$-actin expression in $\alpha$ TC1 cells, mouse islets, and mouse kidney ( $\mathrm{n}=3$ per group). Data are the mean \pm SD. (C) Direct sequencing of whole RNA samples for SGLT2 expression in $\alpha$ TC1 cells, mouse islets, and mouse kidney. $(\mathrm{D}-\mathrm{G})$ Representative images of immunostained tissue sections of mouse pancreas $(\mathrm{D})$, human type 2 diabetic pancreas $(\mathrm{E})$, mouse kidney $(\mathrm{F})$, and human kidney (G) for SGLT1 (red), SGLT2 (red), glucagon (green), and insulin (green). Yellow indicates co-localization of SGLT1 and SGLT2 with glucagon or insulin. Blue indicates DAPI. Scale bars $=20 \mu \mathrm{m}$. 
measurements [28]. We found that $10 \mathrm{mg} / \mathrm{kg}$ dapagliflozin and $10 \mathrm{mg} /$ $\mathrm{kg}$ canagliflozin lowered blood glucose levels to the same degree (Figure 1A,B). Nevertheless, this dose of canagliflozin induced less urinary glucose excretion than dapagliflozin (Figure $1 \mathrm{C}$ ). On the other hand, the urinary glucose excretion induced by $30 \mathrm{mg} / \mathrm{kg}$ canagliflozin was almost same as that induced by $10 \mathrm{mg} / \mathrm{kg}$ dapagliflozin (Figure 1C). Although $10 \mathrm{mg} / \mathrm{kg}$ dapagliflozin significantly increased plasma glucagon levels compared to control mice, neither $10 \mathrm{mg} / \mathrm{kg}$ nor $30 \mathrm{mg} / \mathrm{kg}$ canagliflozin increased plasma glucagon levels (Figure 1D). Plasma insulin levels were slightly reduced by $10 \mathrm{mg} / \mathrm{kg}$ canagliflozin (Figure 1E), but plasma GLP-1 levels were not affected by either SGLT2 inhibitor (Figure 1F). We obtained similar results in a diabetic mouse model ( $d b / d b$ mice; Supplementary Figs. 1A-D). However, neither dapagliflozin nor canagliflozin increased plasma glucagon levels in chow-fed, wild-type mice (Supplementary Figs. 1E-H). Thus, the effect of dapagliflozin on glucagon appeared to be specific for the diabetic condition.

\subsection{SGLT1, but not SGLT2, is expressed in $\alpha \mathrm{TC1}$ cells, mouse}

islets, and human islets

Recently, Bonner et al. reported that SGLT1 and SGLT2 were expressed in pancreatic $\alpha$ cells. They showed that dapagliflozin increased plasma glucagon levels by directly inhibiting SGLT2 in $\alpha$ cells [10]. However, SGLT2 was previously thought to be expressed specifically in renal tubule cells. Therefore, we tested our $\alpha \mathrm{TC} 1$ cells and mouse islets to determine whether SGLT1, SGLT2, and GLUT1 were expressed. RT-PCR revealed that SGLT1 and GLUT1 were expressed, but SGLT2 was not expressed, in both $\alpha \mathrm{TC1}$ cells and mouse islets (Figure 2A). We confirmed these results with quantitative real-time RT-PCR (Figure 2B). Furthermore, direct sequencing of whole RNA isolated from $\alpha \mathrm{TC} 1$ cells and mouse islets revealed that SGLT2 sequences were rarely detected in RNA reads, although they were abundantly detected in RNA isolated from the kidney (Figure 2C). These results indicated that pancreatic $\alpha$ cells do not express SGLT2 and that, apparently, dapagliflozin's effects on plasma glucagon were not mediated by direct SGLT2 inhibition in $\alpha$ cells. On the other hand, immunostaining showed that SGLT1 was expressed specifically in $\alpha$ cells, but not in $\beta$ cells, in mouse islets (Figure 2D). Interestingly, not all, but some $\alpha$ cells expressed SGLT1, suggesting heterogeneity among $\alpha$ cells (Figure 2D). We also observed similar expression patterns in human pancreatic sections (Figure 2E). As controls, both SGLT1 and SGLT2 were detected in mouse and human kidney sections (Figure 2F,G).

\subsection{Neither dapagliflozin nor canagliflozin increased plasma glucagon levels under constant blood glucose conditions in HFHSD mice}

As described above, the glucagon-increasing effect of dapagliflozin was not mediated by a direct mechanism in $\alpha$ cells. Therefore, we hypothesized that dapagliflozin might increase glucagon through an indirect mechanism that sensed acute declines in blood glucose levels. To test this hypothesis, we performed a glucose clamp experiment in HFHSD mice. We reasoned that, if dapagliflozin's effect was mediated by a compensation mechanism, which responded to an acute decline in blood glucose, then, under constant blood glucose clamp conditions, dapagliflozin would not increase plasma glucagon levels. As shown in Figure 3A,B, neither $10 \mathrm{mg} / \mathrm{kg}$ dapagliflozin nor $10 \mathrm{mg} / \mathrm{kg}$ canagliflozin increased plasma glucagon levels under clamp conditions. Importantly, the glucose infusion rate during the glucose clamp was higher in dapagliflozin-treated mice than in canagliflozin-treated mice (Figure $3 \mathrm{C}$ ). This finding was consistent with former results that
A

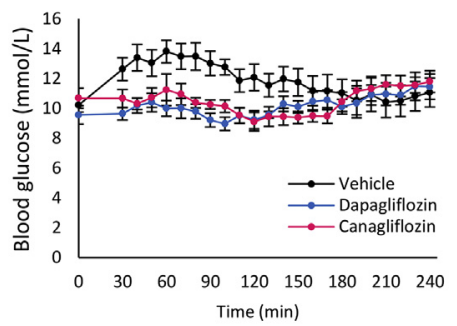

B

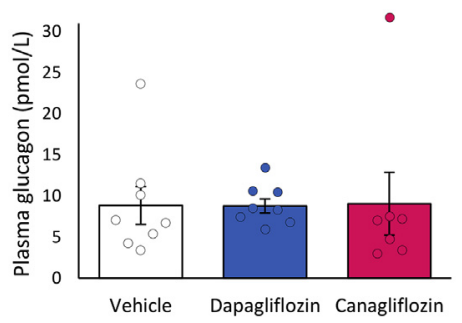

C

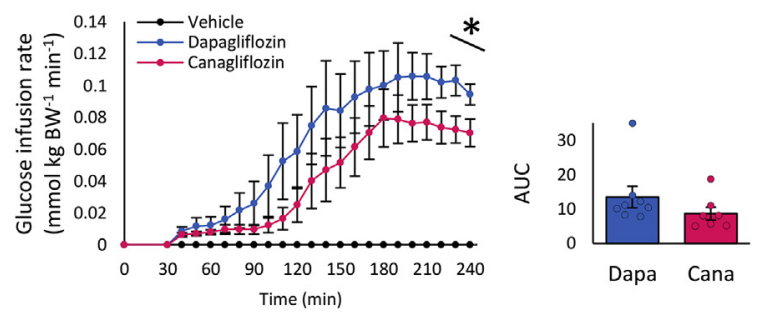

Figure 3: Neither dapagliflozin nor canagliflozin increased plasma glucagon levels under constant blood glucose conditions in HFHSD mice. Measurements taken during glucose clamp studies performed for $4 \mathrm{~h}$ after treatment with vehicle, $10 \mathrm{mg} / \mathrm{kg}$ dapagliflozin, or $10 \mathrm{mg} / \mathrm{kg}$ canagliflozin in HFHSD mice at 20-weeks of age. (A) Time course of blood glucose; (B) plasma glucagon measured at $4 \mathrm{~h}$ after drug administration; (C) time course of glucose infusion rates with area under the curve (AUC). Data are the mean \pm SE ( $n=7$ or 8 mice in each group). ${ }^{*} p<0.05$ vs. canagliflozin-treated group.

showed higher urine glucose excretions in dapagliflozin-treated mice than in canagliflozin-treated mice (Figure 1C). These results suggested that dapagliflozin increased plasma glucagon through a compensation mechanism that sensed acute declines in blood glucose. In other words, despite the fact that $10 \mathrm{mg} / \mathrm{kg}$ dapagliflozin induced greater urinary glucose excretion than $10 \mathrm{mg} / \mathrm{kg}$ canagliflozin, these two SGLT2 inhibitors had comparable blood glucose-lowering effects, possibly due to the compensatory glucagon secretion induced by dapagliflozin, but not canagliflozin.

\subsection{Canagliflozin suppressed glucagon secretion by inhibiting} SGLT1 in aTC1 cells and mouse islets

We next addressed the question of why a compensatory increase in plasma glucagon was not observed in canagliflozin-treated mice, despite the fact that canagliflozin and dapagliflozin induced the same degree of decline in blood glucose. We noted that the selectivities for SGLT2 are different between dapagliflozin and canagliflozin (canagliflozin is less selective for SGLT2 than dapagliflozin) and that SGLT1 is indeed expressed in $\alpha$ cells (Figure 2A, B, D, E). Therefore, we hypothesized that canagliflozin, a SGLT2/low-potency-SGLT1 inhibitor, might suppress glucagon secretion by inhibiting SGLT1 in $\alpha$ cells; canagliflozin did not increase plasma glucagon levels in HFHSD mice or $d b / d b$ mice, even under conditions of declining blood glucose. To test this hypothesis, we incubated $\alpha \mathrm{TC1}$ cells with canagliflozin or 
dapagliflozin. Previous reports indicated that $300 \mathrm{mg}$ canagliflozin, the clinical daily dose, produced a peak plasma concentration of 7.8$10 \mu \mathrm{M}$ in humans $[26,31]$. Therefore, we tested two concentrations, 2 and $20 \mu \mathrm{M}$. After $2 \mathrm{~h}$ incubations, both 2 and $20 \mu \mathrm{M}$ canagliflozin, significantly decreased glucagon secretion from $\alpha \mathrm{TC} 1$ cells (Figure 4A). In contrast, dapagliflozin did not affect glucagon secretion at either 2 or $20 \mu \mathrm{M}$, but $200 \mu \mathrm{M}$ dapagliflozin significantly inhibited glucagon secretion (Figure 4A). Based on the fact that $20 \mathrm{mg}$ dapagliflozin, a double clinical daily dose, was known to produce peak plasma concentrations of only $0.7 \mu \mathrm{M}$ in humans [26,32], we assumed that $200 \mu \mathrm{M}$ dapagliflozin was an overdose compared to the clinical dose. Consistent with these results, $2 \mu \mathrm{M}$ canagliflozin, but not $2 \mu \mathrm{M}$ dapagliflozin, inhibited glucagon secretion in isolated mouse islets in both $1 \mathrm{mM}$ and $5 \mathrm{mM}$ glucose conditions (Figure 4B). In addition, a non-selective SGLT inhibitor, sotagliflozin, which inhibits both SGLT2 and SGLT1, also significantly inhibited glucagon secretion in $\alpha \mathrm{TC1}$ cells (Figure $4 \mathrm{C}$ ).

To investigate further whether canagliflozin suppression of glucagon was mediated by SGLT1 inhibition, we knocked down SGLT1 in aTC1 cells. Cells transfected with SGLT1-siRNA displayed $80 \%$ reductions in

A

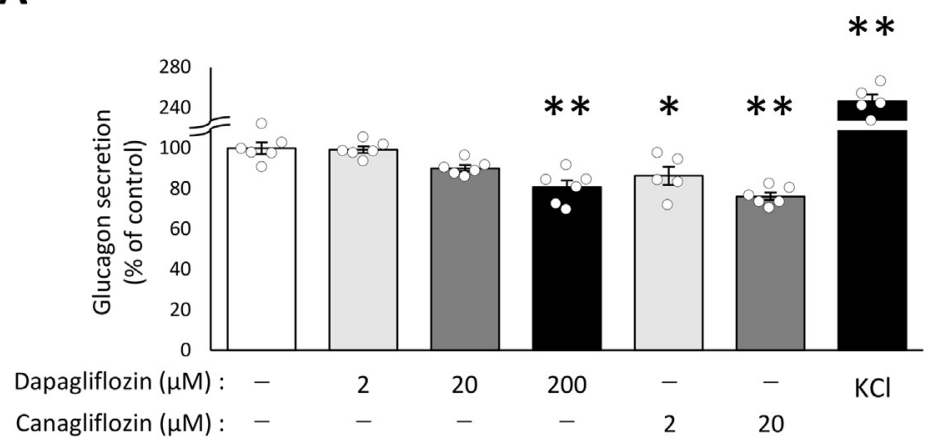

B

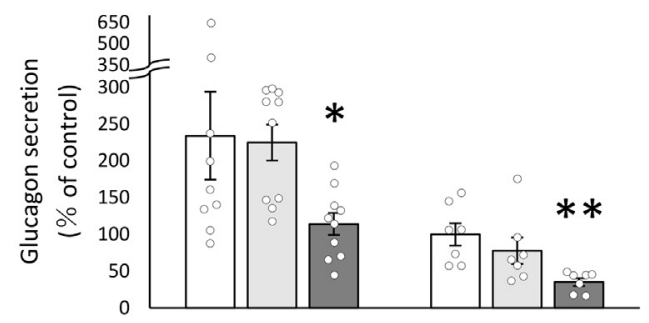

Glucose $(\mathrm{mM}): \begin{array}{lll}1 & 1 & 1\end{array}$ Dapagliflozin $(2 \mu \mathrm{M}):-\quad+-$ Canagliflozin $(2 \mu \mathrm{M}):-\quad-\quad+$

D

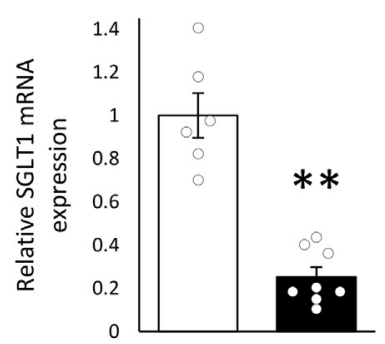

siRNA : scrambled SGLT1

scrambled SGLT1
E

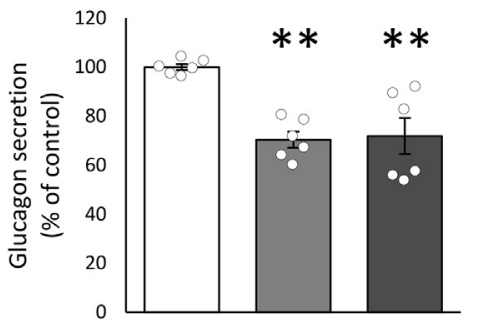

Canagliflozin $(20 \mu \mathrm{M}): \quad-\quad+\quad+$ Sotagliflozin $(20 \mu M):-\quad-\quad-\quad+$

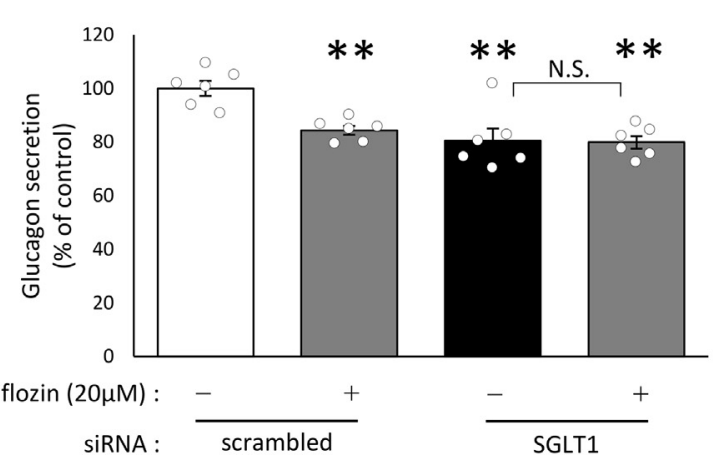

Figure 4: Canagliflozin and sotagliflozin suppressed glucagon secretion by inhibiting SGLT1 in $\alpha$ TC1 cells and mouse islets. (A) Glucagon secretion from $\alpha$ TC1 cells during $2 \mathrm{~h}$ incubations with or without dapagliflozin, canagliflozin or $\mathrm{KCl}(60 \mathrm{mM})$ at the indicated concentrations $(\mathrm{n}=5-6)$. (B) Glucagon secretion from 10 size-matched mouse islets during $2 \mathrm{~h}$ incubations without or with $2 \mu \mathrm{M}$ dapagliflozin or canagliflozin under $1 \mathrm{mM}$ or $5 \mathrm{mM}$ glucose conditions $(\mathrm{n}=7-10)$. (C) Glucagon secretion from $\alpha \mathrm{TC} 1 \mathrm{cells}$ during $2 \mathrm{~h}$ incubations with or without $20 \mu \mathrm{M}$ canagliflozin or sotagliflozin $(\mathrm{n}=6)$. (D) Relative SGLT1 mRNA expression in $\alpha$ TC1 cells transfected with SGLT1 siRNA or scrambled siRNA $(n=6-8)$. (E) Glucagon secretion from $\alpha$ TC1 cells transfected with SGLT1 siRNA or scrambled siRNA, then incubated for $2 \mathrm{~h}$ with or without $20 \mu \mathrm{M}$ canagliflozin ( $\mathrm{n}=6$ ). Data are the mean \pm SE. ${ }^{\star} p<0.05,{ }^{\star \star} p<0.01$; vs. respective control. N.S.; not significant. 
SGLT1 mRNA levels (Figure 4D) and exhibited significantly reduced glucagon secretion (Figure 4E). Importantly, canagliflozin did not further suppress glucagon secretion in SGLT1-knock-down $\alpha$ TC1 cells (Figure 4E). This result suggested that canagliflozin directly suppressed glucagon secretion by inhibiting SGLT1 in $\alpha$ cells.

\subsection{Canagliflozin suppressed glucagon secretion depending on glucose transport, but not glucose metabolism}

Because SGLT1 is a sodium/glucose cotransporter, we next asked which inhibition of glucose transport or glucose metabolism was pivotal for the effect of canagliflozin. In the absence of glucose, canagliflozin had no effect on glucagon secretion in $\alpha \mathrm{TC} 1$ cells (Figure 5A). Importantly, when glucose was replaced with $\alpha \mathrm{MG}$, a nonmetabolizable glucose analog as well as a specific substrate for SGLTs [20,24], canagliflozin could suppress glucagon secretion. In contrast, when glucose was replaced to mannitol, a non-transportable
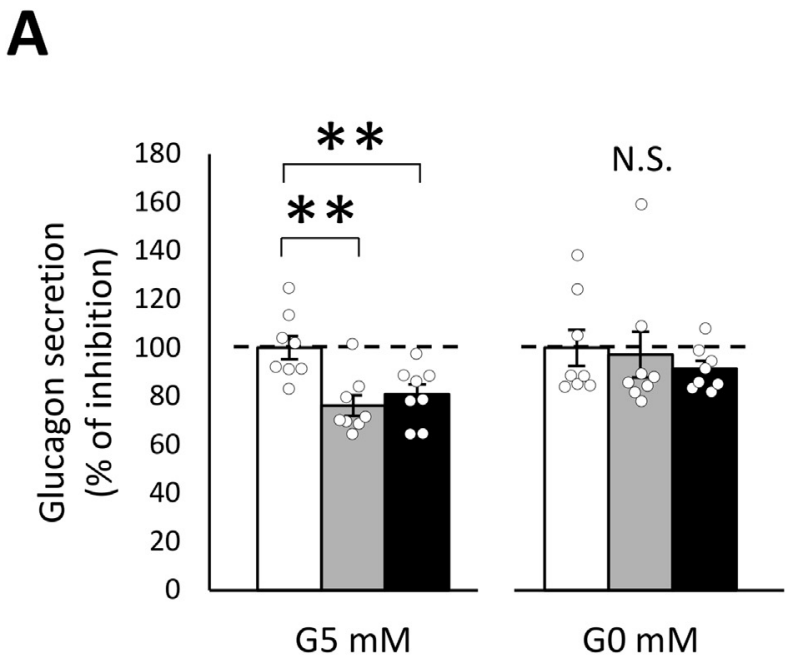

B

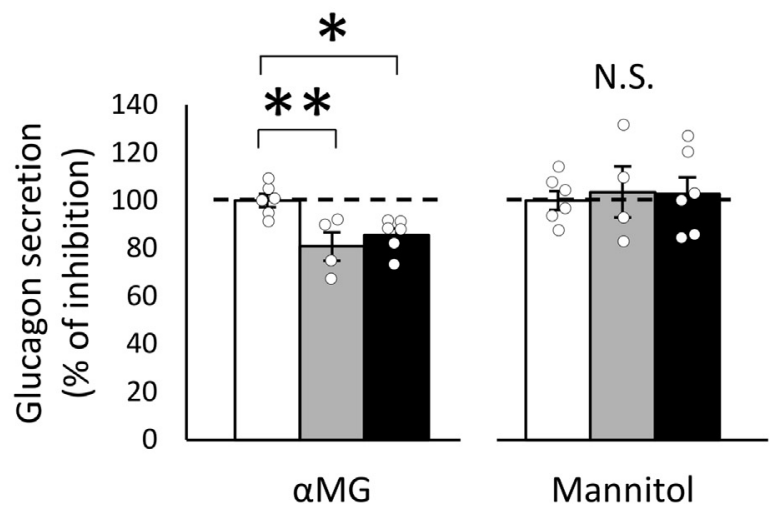

Figure 5: Canagliflozin suppressed glucagon secretion depending on glucose transport, but not glucose metabolism. (A) Glucagon secretion from $\alpha \mathrm{TC} 1$ cells incubated with or without canagliflozin, in the presence or absence of $5 \mathrm{mM}$ glucose $(n=8)$. (B) Glucagon secretion from $\alpha T C 1$ cells incubated with or without canagliflozin in the presence or absence of $100 \mathrm{mM} \alpha \mathrm{MG}$ or $100 \mathrm{mM}$ mannitol instead of glucose ( $\mathrm{n}=4-6$ ). The white, gray, and black bars indicate 0,2 , and $20 \mu \mathrm{M}$ canagliflozin, respectively. Data are the mean $\pm \mathrm{SE}$. ${ }^{\star} p<0.05,{ }^{\star \star} p<0.01$; vs. respective control. N.S.; not significant. sugar, canagliflozin did not affect glucagon secretion (Figure 5B). These results suggested that canagliflozin's effect did not depend on the metabolic effect of glucose but depended on substrate transport. Thus, canagliflozin suppressed glucagon secretion by inhibiting SGLT1-mediated sodium/glucose cotransport.

\subsection{Canagliflozin suppressed $\alpha \mathrm{MG}$-induced intracellular $\mathrm{Ca}^{2+}$ increase in $\alpha \mathrm{TC} 1$ cells}

Because it has been reported that SGLT1-mediated sodium/glucose cotransport depolarizes the membrane and stimulates $\mathrm{Ca}^{2+}$ entry, which results in enhancing GLP-1 secretion in intestinal cells [20-24], we assessed intracellular calcium concentrations in $\alpha \mathrm{TC1}$ cells. As shown in Figure $6 \mathrm{~A}, \alpha \mathrm{MG}$ increased $\left[\mathrm{Ca}^{2+}\right]_{\mathrm{i}}$, that was inhibited by canagliflozin but not dapagliflozin (Figure 6B-D). Interestingly, this inhibition was canceled as soon as canagliflozin removed (Figure 6E,F). These results suggested that canagliflozin suppresses glucagon secretion by inhibiting $\mathrm{Ca}^{2+}$ entry in $\alpha$ cells.

\subsection{Islets from HFHSD mice and $d b / d b$ mice expressed higher SGLT1 and lower GLUT1 mRNA levels, which was associated with increased glucagon secretion, compared to controls}

We next investigated the physiological relevance between the mRNA levels of SGLT1/GLUT1 and the glucagon secretion levels observed in diabetic mice. As shown in Figure 7A, SGLT1 mRNA levels increased, and GLUT1 mRNA levels decreased, in aTC1 cells cultured in high glucose conditions. Consistent with these results, we observed higher SGLT1 mRNA levels and lower GLUT1 mRNA levels in the islets of HFHSD mice (Figure 7B) and $d b / d b$ mice (Figure $7 \mathrm{C}$ ), compared to the islets of control mice. Importantly, the higher SGLT1 and lower GLUT1 mRNA levels were associated with higher glucagon secretion from islets of HFHSD mice (Figure 7D) and $d b / d b$ mice (Figure 7E) compared to control islets. These results suggested that SGLT1 and GLUT1 might play important roles in the regulation of glucagon secretion in $\alpha$ cells. To investigate the roles of SGLT1 and GLUT1 in the regulation of glucagon secretion in mouse islets, we treated the islets with the nonselective SGLT inhibitor, sotagliflozin, or the GLUT inhibitor, phloretin. Glucagon secretion in mouse islets was decreased by $70 \%$ with sotagliflozin, and it was increased by 1.7-fold with phloretin (Figure 7F). We also found that a $\sim 40 \%$ reduction in SGLT1 mRNA levels using siRNA was associated with a $50 \%$ reduction in glucagon secretion (Figure $7 \mathrm{G}$ ). These results indicated that SGLT1 is an important regulator of glucagon secretion in $\alpha$ cells; thus, increases in SGLT1 expression might explain the elevated glucagon secretion observed in diabetic mice.

\section{DISCUSSION}

The present study described five novel findings; $(I)$ dapagliflozin, but not canagliflozin, increased plasma glucagon levels in diabetic mice; (ii) SGLT1, but not SGLT2, was expressed in pancreatic $\alpha$ cells in mouse and human; (iii) dapagliflozin-induced increases in plasma glucagon were driven by a compensatory mechanism that responded to acute declines in blood glucose; (iv) canagliflozin suppressed glucagon secretion in $\alpha \mathrm{TC} 1$ cells by inhibiting SGLT1 in a glucose transport-dependent and intracellular $\mathrm{Ca}^{2+}$ increase-dependent manner; and $(v)$ increased SGLT1 mRNA levels in $\alpha$ cells was associated with higher glucagon secretion in diabetic models.

Consistent with previous reports [10,12], our study showed that dapagliflozin increased plasma glucagon levels in HFHSD mice and $\mathrm{db} /$ $d b$ mice. Bonner et al. proposed that SGLT2 was expressed in $\alpha \mathrm{TC1}$ cells, mouse islets, and human islets, and that dapagliflozin increased 
A

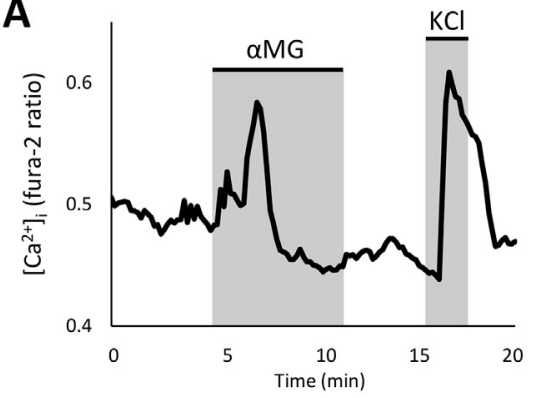

C

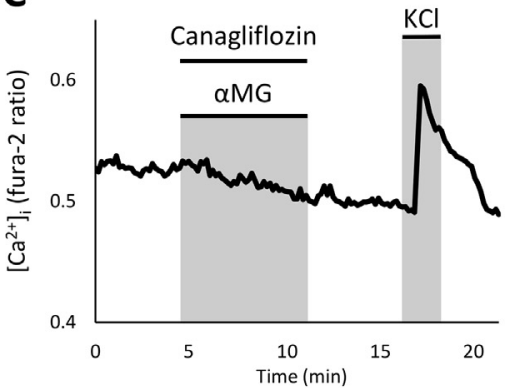

$\mathbf{E}$

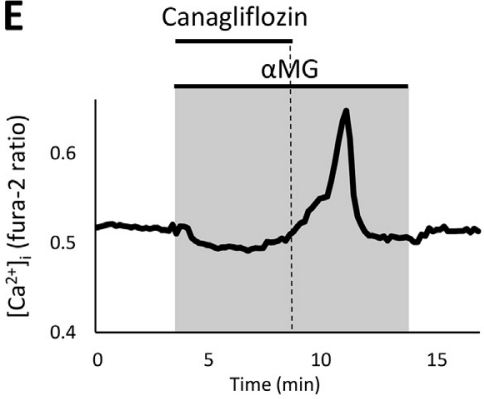

B

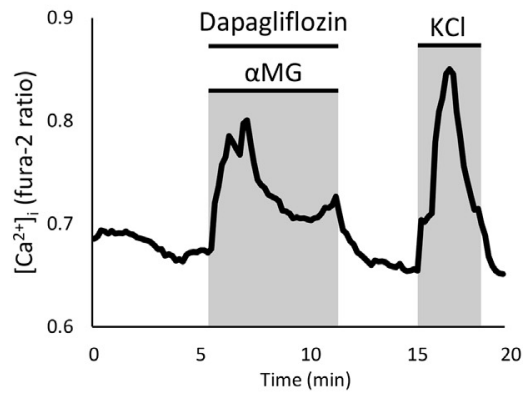

D

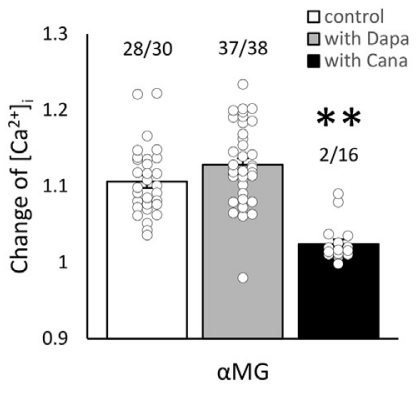

$\mathbf{F}$

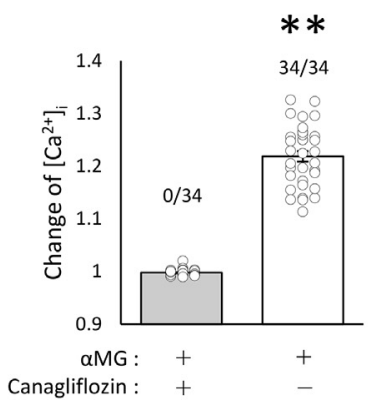

Figure 6: Canagliflozin suppressed $\alpha \mathrm{MG}$-induced $\left[\mathrm{Ca}^{2+}\right]_{\mathrm{i}}$ increase in $\alpha \mathrm{TC1}$ cells. $(\mathrm{A}-\mathrm{C})$ Representative tracing of $100 \mathrm{mM} \alpha \mathrm{MG}$-induced $\left[\mathrm{Ca}^{2+}\right]_{\mathrm{i}}$ increase $(\mathrm{A})$, with $2 \mu \mathrm{M}$ dapagliflozin (B), or $2 \mu \mathrm{M}$ canagliflozin (C) in $\alpha \mathrm{TC1}$ cells, as indicated by assessing ratios of Fura-2 emission at $340 \mathrm{~nm}$ and $380 \mathrm{~nm}$. (D) Quantification of the change of $100 \mathrm{mM}$ aMG-induced $\left[\mathrm{Ca}^{2+}\right]_{i}$ increases $(n=30)$, with $2 \mu \mathrm{M}$ dapagliflozin $(n=38)$, or $2 \mu \mathrm{M}$ canagliflozin $(n=16)$. $(E$, F) Representative tracing $(E)$ and quantification of the change $(F)$ of $100 \mathrm{mM} \propto \mathrm{MG}$-induced $\left[\mathrm{Ca}^{2+}\right]_{i}$ increases before and after the removal of $2 \mu \mathrm{M}$ canagliflozin $(n=34)$. The data of quantification of the change of $\left[\mathrm{Ca}^{2+}\right]_{i}$ increases were calculated by dividing the peak $\left[\mathrm{Ca}^{2+}\right]_{i}$ by the basal $\left[\mathrm{Ca}^{2+}\right]_{i}$. The numbers above each bar indicate the number of cells that responded over the number of cells examined. Cells that increased $\left[\mathrm{Ca}^{2+}\right]_{\text {i }}$ more than $5 \%$ compared to the basal $\left[\mathrm{Ca}^{2+}\right]_{\text {i }}$ were considered to be responded. Data are the mean $\pm \mathrm{SE} .{ }^{\star} p<0.05,{ }^{\star \star} p<0.01$; vs. respective control.

glucagon secretion by directly inhibiting SGLT2 in $\alpha$ cells [10]. However, we did not detect SGLT2 expression in $\alpha$ TC1 cells, mouse islets and human islets (Figure 2A-E). Our results are supported by recent report, which discloses single cell transcriptome profiling of human pancreatic islets in healthy and type 2 diabetes patients [33]. These data sets also show SLC5A2 (which encodes SGLT2) is rarely detectable in pancreatic $\alpha$ cells. Furthermore, glucagon secretion was not stimulated by dapagliflozin in $\alpha \mathrm{TC1}$ cells or mouse islets (Figure 4A,B). Therefore, our results suggested that it was unlikely that dapagliflozin's effect on plasma glucagon was mediated by direct inhibition of SGLT2 in $\alpha$ cells. Alternatively, based on our glucose clamp experiment results, we proposed that dapagliflozin might trigger a mechanism that compensated for acute declines in blood glucose levels, and this mechanism could account for the increases in plasma glucagon. This proposal was consistent with a previous report that showed that acute declines in blood glucose concentrations (induced by insulin), even under hyperglycemic conditions, induced glucagon secretion in patients with type 2 diabetes [34]. Importantly, dapagliflozin increased glucagon secretion only in diabetic mice, not in control mice; probably because the effects of SGLT2 inhibitors were augmented under diabetic conditions.

Our interpretation for the results of Figure 1 is as follows; $10 \mathrm{mg} / \mathrm{kg}$ dapagliflozin had more urinary glucose excretion than $10 \mathrm{mg} / \mathrm{kg}$ canagliflozin (Figure 1C). However, $10 \mathrm{mg} / \mathrm{kg}$ dapagliflozin also increased plasma glucagon (Figure 1D), which might have partly offset the blood glucose lowering effect induced by urinary glucose excretion (Figure 1A-B). By contrast, because $10 \mathrm{mg} / \mathrm{kg}$ canagliflozin did not increase plasma glucagon (Figure 1D), blood glucose levels were directly affected by the urinary glucose excretion (Figure $1 \mathrm{~A}-\mathrm{C}$ ). We summarized these observations in Supplementary Figure 2.

Intriguingly, canagliflozin did not increase plasma glucagon levels, even though canagliflozin and dapagliflozin reduced blood glucose and increased urinary glucose excretion to the same extents. We considered that it was unlikely that a secondary suppression of glucagon was mediated by insulin [7] or GLP-1 [35,36], because canagliflozin appeared to reduce plasma insulin levels and it did not alter the active GLP-1 levels (Figure 1E,F). A previous study showed that canagliflozin increased "postprandial" plasma GLP-1 levels [37]. On the other hand, 
A

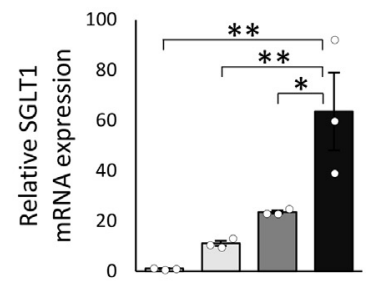

Glucose (mM) : $\begin{array}{llll}5 & 11 & 18 & 25\end{array}$

B

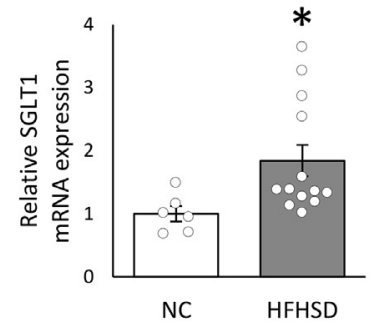

C

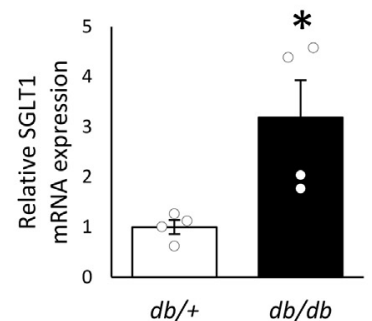

D

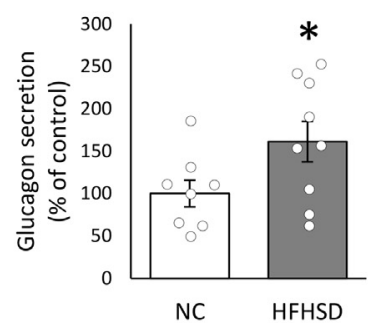

$\mathbf{F}$

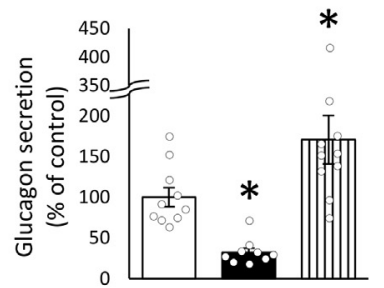

Sotagliflozin $(20 \mu \mathrm{M})$ :

Phloretin $(300 \mu \mathrm{M})$ :

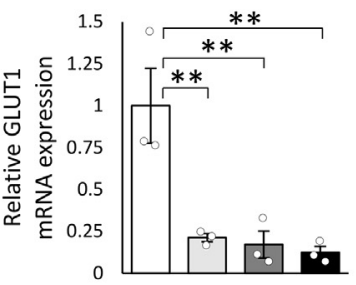

Glucose (mM) : $5 \quad 11 \quad 18 \quad 25$
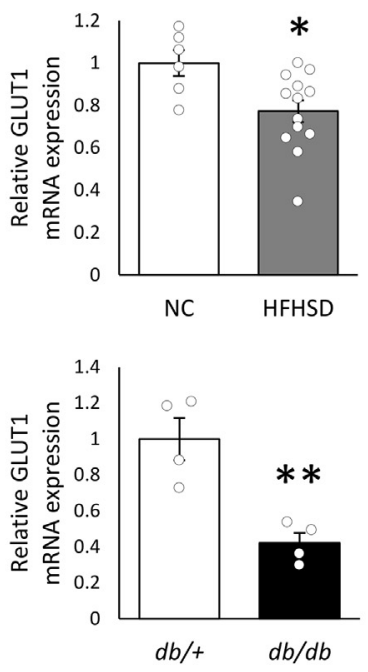

E

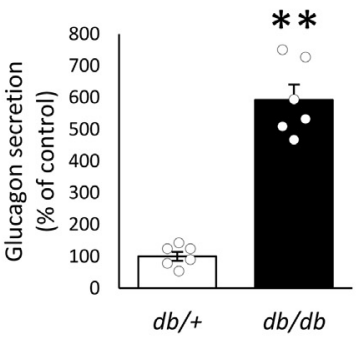

G

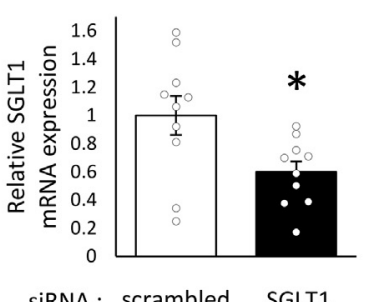

siRNA : scrambled SGLT1

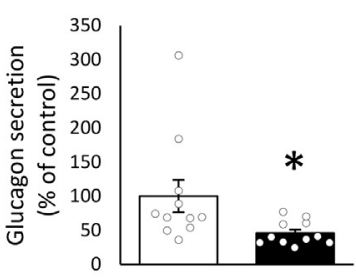

siRNA : scrambled SGLT1

Figure 7: Increased SGLT1, decreased GLUT1 mRNA levels in the islets of HFHSD mice and $d \boldsymbol{d b} / d \boldsymbol{b}$ mice, compared to control mice. (A) Relative SGLT1 and GLUT1 mRNA expression in $\alpha$ TC1 cells cultured with 5, 11, 18, or $25 \mathrm{mM}$ glucose for $48 \mathrm{~h}(\mathrm{n}=3$ per group). (B) Relative SGLT1 and GLUT1 mRNA expression in islets from mice fed NC ( $\mathrm{n}=6$ ) or HFHSD ( $n=13)$, at the age of 22-weeks. (C) Relative SGLT1 and GLUT1 mRNA expression in islets from non-diabetic controls $(d b /+)$ or diabetic ( $d b / d b)$ mice, at the age of 16weeks $(n=4)$. (D) Glucagon secretion from islets of NC or HFHSD mice in $5 \mathrm{mM}$ glucose conditions $(n=8-9)$. (E) Glucagon secretion from islets of $d b /+$ or $d b / d b$ mice $(n=6)$. (F) Glucagon secretion from islets incubated with or without $20 \mu \mathrm{M}$ sotagliflozin or $300 \mu \mathrm{M}$ phloretin $(\mathrm{n}=9-10)$. (G) Relative SGLT1 mRNA expression (n $=10)$ or glucagon secretion $(n=11)$ in mouse islets transfected with SGLT1 siRNAs or scrambled siRNA. Data are the mean \pm SE relative to controls or the mean \pm SE percentage of control group values. ${ }^{\star} p<0.05,{ }^{\star \star} p<0.01$; vs. respective control.

a recent report showed that the oral administration of canagliflozin enhanced GLP-1 secretion by increasing the glucose delivery to lower part of the small intestine. Moreover, in this report canagliflozin showed no direct effect on GLP-1 release in vitro [38]. Because food was removed from the cages before drug administration in our experiment, canagliflozin might not have increased plasma active GLP1 levels.
Because we showed that canagliflozin (but not dapagliflozin) suppressed glucagon secretion in $\alpha \mathrm{TC} 1$ cells by inhibiting SGLT1, we suspect that the compensatory increase in glucagon secretion might have been canceled due to the direct suppression of glucagon secretion by canagliflozin. This idea might be partly supported by the recent report that SGLT1 knockout mice did not increase plasma glucagon levels even under the glucagon increasing conditions in control mice [39]. In 
addition, a recent clinical trial showed that canagliflozin treatment did not increase plasma glucagon in T2DM patients [40].

The issue of whether a clinical dose of canagliflozin might inhibit SGLT1 in $\alpha$ cells in vivo, remains under debate. First, consider the effective concentration produced with a $300 \mathrm{mg}$ dose of canagliflozin, which is a clinical daily dose. This dose was reported to produce a peak plasma concentration of $7.8-10 \mu \mathrm{M}$ in humans [26,31]. However, $\sim 98 \%$ of canagliflozin binds to plasma proteins [26], which results in a free canagliflozin concentration of $156-200 \mathrm{nM}$ in plasma. This effective concentration is below the $\mathrm{IC}_{50}(684-710 \mathrm{nM})$ of canagliflozin for SGLT1 inhibition in humans [26]. Therefore, it remains unclear whether a clinical dose of canagliflozin would inhibit SGLT1 in $\alpha$ cells, when administered in patients. On the other hand, the selectivity of dapagliflozin for SGLT2 is much higher than that of canagliflozin. Thus, a clinical dose of dapagliflozin would be unlikely to inhibit SGLT1, and thus, dapagliflozin would not be expected to affect glucagon secretion in $\alpha$ cells.

We showed that canagliflozin suppression of glucagon secretion depended on glucose transport, but not on glucose metabolism. These results indicated that the influx of a SGLT substrate (probably $\mathrm{Na}^{+}$) through SGLT1 was associated with glucagon secretion. This mechanism was reminiscent of one previously described regarding GLP-1 secretion in intestinal $L$ cells. The mechanism for GLP-1 secretion via SGLT1 was proposed as follows; an increased influx of SGLT substrates generated an inward current, which depolarized the membrane and stimulated $\mathrm{Ca}^{2+}$ entry [20-24]. This same mechanism could be applicable to glucagon secretion in $\alpha$ cells. Actually, we showed that non-metabolizable SGLTs specific substrate $\alpha M G$ increased $\left[\mathrm{Ca}^{2+}\right]_{i}$ in $\alpha \mathrm{TC} 1$ cells (Figure $6 \mathrm{~A}$ ), suggesting that a influx of SGLT1 substrates could be associated with glucagon secretion. It was also reported that SGLT1 acted as the luminal glucose sensor in L cells, even though the intracellular glucose concentration was largely determined by GLUT activity [21].

We showed that SGLT1 was predominantly expressed in the $\alpha$ cells of mouse islets and human islets (Figure 2D,E), and the SGLT1 mRNA levels were likely correlated with the levels of glucagon secretion (Figure $7 \mathrm{~A}-\mathrm{G}$ ). Interestingly, we found that SGLT1 and GLUT1 mRNA displayed opposite expression patterns in the islets of HFHSD mice and $d b / d b$ mice. Furthermore, when SGLT1 was inhibited by sotagliflozin, glucagon secretion was suppressed, but when GLUT1 was inhibited by phloretin, glucagon secretion was enhanced in mouse islets. This result suggested that SGLT1 and GLUT1 might contribute to the regulation of glucagon secretion with opposing signals. Considering that SGLT1 mRNA levels in $\alpha$ cells was elevated under high glucose and diabetic conditions, and that elevated SGLT1 mRNA levels was associated with increased glucagon secretion, we suggest that increased SGLT1 expression in $\alpha$ cells might represent an etiology of hyperglucagonemia observed in the patients of type 2 diabetes. However, further studies will be needed to elucidate this important issue.

Finally, our findings had some clinical implications. First, because clinical trials have shown that both canagliflozin and dapagliflozin improved clinical outcomes in patients with type 2 diabetes [40-44], it remains unclear whether the different effects on glucagon secretion might be clinically relevant in diabetes therapy. On the other hand, SGLT2 inhibitors were also expected to be applicable to cancer therapy $[45,46]$ and nonalcoholic fatty liver disease treatments [47]. Considering that glucagon can affect the growth of cancer cells [48-50], and that nonalcoholic fatty liver disease is often accompanied by fasting hyperglucagonemia [51], glucagon might be related to the pathophysiology of those diseases. Thus, we expect that the results of the present study might have important implications for the classification and selection of SGLT2 inhibitors in the treatment of various diseases, in addition to diabetes.

\section{CONCLUSIONS}

Our results suggest that a novel mechanism regulated glucagon secretion through SGLT1 in $\alpha$ cells. This finding possibly explained the distinct effects of dapagliflozin and canagliflozin on plasma glucagon levels in mice, and might provide implications for the classification and selection of SGLT2 inhibitors in the treatment of diabetes. Moreover, SGLT1 in $\alpha$ cells might contribute to the mechanism underlying hyperglucagonemia in diabetic patients, which requires further research in order to be elucidated.

\section{AUTHOR CONTRIBUTIONS}

T. Suga collected, analyzed, interpreted the data, and drafted the article; 0 . Kikuchi performed and analyzed the clamp studies and reviewed the data; K. Takeuchi supplied the Glucagon ELISA Kit; M. Kobayashi, S. Matsui, H. Hashimoto, E. Wada, D. Kohno, T. Sasaki, S. Kakizaki, and M. Yamada reviewed the data; and T. Kitamura designed and conceived the experiments, reviewed the data, edited the article, and approved the version to be published.

\section{FUNDING}

This work was financially supported by the Mitsubishi Tanabe Pharma Corporation and AstraZeneca K.K. (Japan).

\section{ACKNOWLEDGEMENTS}

We thank Ms Satoko Hashimoto for providing skilled technical assistance in immunohistochemistry. We also thank Prof. Y. Fujitani (Laboratory of Developmental Biology \& Metabolism, Institute for Molecular and Cellular Regulation, Gunma University) and members of his laboratory for critical discussions of the data. We also thank Dr A. Kushida for assistance in glucagon assays.

\section{CONFLICT OF INTEREST}

None declared.

\section{APPENDIX A. SUPPLEMENTARY DATA}

Supplementary data to this article can be found online at https://doi.org/10.1016/j. molmet.2018.10.009.

\section{REFERENCES}

[1] Campbell, J.E., Drucker, D.J., 2015. Islet alpha cells and glucagon-critical regulators of energy homeostasis. Nature Reviews Endocrinology 11:329-338.

[2] Baron, A.D., Schaeffer, L., Shragg, P., Kolterman, 0.G., 1987. Role of hyperglucagonemia in maintenance of increased rates of hepatic glucose output in type II diabetics. Diabetes 36:274-283.

[3] Shah, P., Vella, A., Basu, A., Basu, R., Schwenk, W.F., Rizza, R.A., 2000. Lack of suppression of glucagon contributes to postprandial hyperglycemia in subjects with type 2 diabetes mellitus. The Journal of Cinical Endocrinology and Metabolism 85:4053-4059.

[4] Hancock, A.S., Du, A., Liu, J., Miller, M., May, C.L., 2010. Glucagon deficiency reduces hepatic glucose production and improves glucose tolerance in adult mice. Molecular Endocrinology 24:1605-1614. 
[5] Unger, R.H., Cherrington, A.D., 2012. Glucagonocentric restructuring of diabetes: a pathophysiologic and therapeutic makeover. Journal of Clinical Investigation 122:4-12.

[6] Vieira, E., Salehi, A., Gylfe, E., 2007. Glucose inhibits glucagon secretion by a direct effect on mouse pancreatic alpha cells. Diabetologia 50:370-379.

[7] Ravier, M.A., Rutter, G.A., 2005. Glucose or insulin, but not zinc ions, inhibit glucagon secretion from mouse pancreatic alpha-cells. Diabetes 54:1789-1797.

[8] Le Marchand, S.J., Piston, D.W., 2010. Glucose suppression of glucagon secretion: metabolic and calcium responses from alpha-cells in intact mouse pancreatic islets. Journal of Biological Chemistry 285:14389-14398.

[9] Heimberg, H., De Vos, A., Pipeleers, D., Thorens, B., Schuit, F., 1995. Differences in glucose transporter gene expression between rat pancreatic alphaand beta-cells are correlated to differences in glucose transport but not in glucose utilization. Journal of Biological Chemistry 270:8971-8975.

[10] Bonner, C., Kerr-Conte, J., Gmyr, V., Queniat, G., Moerman, E., Thevenet, J., et al., 2015. Inhibition of the glucose transporter SGLT2 with dapagliflozin in pancreatic alpha cells triggers glucagon secretion. Natura Medica 21:512-517.

[11] Wright, E.M., 2013. Glucose transport families SLC5 and SLC50. Molecular Aspects of Medicine 34:183-196.

[12] Merovci, A., Solis-Herrera, C., Daniele, G., Eldor, R., Fiorentino, T.V., Tripathy, D., et al., 2014. Dapagliflozin improves muscle insulin sensitivity but enhances endogenous glucose production. Journal of Clinical Investigation 124:509-514.

[13] Ferrannini, E., Muscelli, E., Frascerra, S., Baldi, S., Mari, A., Heise, T., et al., 2014. Metabolic response to sodium-glucose cotransporter 2 inhibition in type 2 diabetic patients. Journal of Clinical Investigation 124:499-508.

[14] Pedersen, M.G., Ahlstedt, I., El Hachmane, M.F., Gopel, S.0., 2016. Dapagliflozin stimulates glucagon secretion at high glucose: experiments and mathematical simulations of human A-cells. Scientific Reports 6:31214.

[15] Hattersley, A.T., Thorens, B., 2015. Type 2 diabetes, SGLT2 inhibitors, and glucose secretion. New England Journal of Medicine 373:974-976.

[16] Kibbey, R.G., 2015. SGLT-2 inhibition and glucagon: cause for alarm? Trends in Endocrinology and Metabolism 26:337-338.

[17] Solini, A., Sebastiani, G., Nigi, L., Santini, E., Rossi, C., Dotta, F., 2017. Dapagliflozin modulates glucagon secretion in an SGLT2-independent manner in murine alpha cells. Diabetes and Metabolism 43:512-520.

[18] Jurczak, M.J., Lee, H.Y., Birkenfeld, A.L., Jornayvaz, F.R., Frederick, D.W., Pongratz, R.L., et al., 2011. SGLT2 deletion improves glucose homeostasis and preserves pancreatic beta-cell function. Diabetes 60:890-898.

[19] Ueta, K., O’Brien, T.P., McCoy, G.A., Kim, K., Healey, E.C., Farmer, T.D., et al., 2014. Glucotoxicity targets hepatic glucokinase in Zucker diabetic fatty rats, a model of type 2 diabetes associated with obesity. American Journal of Physiology Endocrinology and Metabolism 306:E1225-E1238.

[20] Gribble, F.M., Williams, L., Simpson, A.K., Reimann, F., 2003. A novel glucosesensing mechanism contributing to glucagon-like peptide-1 secretion from the GLUTag cell line. Diabetes 52:1147-1154.

[21] Parker, H.E., Adriaenssens, A., Rogers, G., Richards, P., Koepsell, H., Reimann, F., et al., 2012. Predominant role of active versus facilitative glucose transport for glucagon-like peptide-1 secretion. Diabetologia 55:2445-2455.

[22] Kuhre, R.E., Frost, C.R., Svendsen, B., Holst, J.J., 2015. Molecular mechanisms of glucose-stimulated GLP-1 secretion from perfused rat small intestine. Diabetes 64:370-382.

[23] Sun, E.W., de Fontgalland, D., Rabbitt, P., Hollington, P., Sposato, L., Due, S.L., et al., 2017. Mechanisms controlling glucose-induced GLP-1 secretion in human small intestine. Diabetes 66:2144-2149.

[24] Gorboulev, V., Schurmann, A., Vallon, V., Kipp, H., Jaschke, A., Klessen, D., et al., 2012. $\mathrm{Na}(+)$-D-glucose cotransporter SGLT1 is pivotal for intestinal glucose absorption and glucose-dependent incretin secretion. Diabetes 61: 187-196.

[25] Fan, X., Chan, O., Ding, Y., Zhu, W., Mastaitis, J., Sherwin, R., 2015. Reduction in SGLT1 mRNA expression in the ventromedial hypothalamus improves the counterregulatory responses to hypoglycemia in recurrently hypoglycemic and diabetic rats. Diabetes 64:3564-3572.

[26] Faillie, J.L., 2017. Pharmacological aspects of the safety of gliflozins. Pharmacological Research 118:71-81.

[27] Bak, M.J., Albrechtsen, N.W., Pedersen, J., Hartmann, B., Christensen, M., Vilsboll, T., et al., 2014. Specificity and sensitivity of commercially available assays for glucagon and oxyntomodulin measurement in humans. European Journal of Endocrinology 170:529-538.

[28] Miyachi, A., Kobayashi, M., Mieno, E., Goto, M., Furusawa, K., Inagaki, T., et al., 2017. Accurate analytical method for human plasma glucagon levels using liquid chromatography-high resolution mass spectrometry: comparison with commercially available immunoassays. Analytical and Bioanalytical Chemistry 409:5911-5918.

[29] Kitamura, T., Kido, Y., Nef, S., Merenmies, J., Parada, L.F., Accili, D., 2001. Preserved pancreatic beta-cell development and function in mice lacking the insulin receptor-related receptor. Molecular and Cellular Biology 21:56245630.

[30] Kohno, D., Koike, M., Ninomiya, Y., Kojima, I., Kitamura, T., Yada, T., 2016. Sweet taste receptor serves to activate glucose- and leptin-responsive neurons in the hypothalamic arcuate nucleus and participates in glucose responsiveness. Frontiers in Neuroscience 10:502.

[31] Devineni, D., Curtin, C.R., Polidori, D., Gutierrez, M.J., Murphy, J., Rusch, S., et al., 2013. Pharmacokinetics and pharmacodynamics of canagliflozin, a sodium glucose co-transporter 2 inhibitor, in subjects with type 2 diabetes mellitus. The Journal of Clinical Pharmacology 53:601-610.

[32] Kasichayanula, S., Chang, M., Hasegawa, M., Liu, X., Yamahira, N., LaCreta, F.P., et al., 2011. Pharmacokinetics and pharmacodynamics of dapagliflozin, a novel selective inhibitor of sodium-glucose co-transporter type 2 , in Japanese subjects without and with type 2 diabetes mellitus. Diabetes Obesity and Metabolism 13:357-365.

[33] Segerstolpe, A., Palasantza, A., Eliasson, P., Andersson, E.M., Andreasson, A.C., Sun, X., et al., 2016. Single-cell transcriptome profiling of human pancreatic islets in health and type 2 diabetes. Cell Metabolism 24: 593-607.

[34] DeFronzo, R.A., Andres, R., Bedsoe, T.A., Boden, G., Faloona, G.A., Tobin, J.D., 1977. A test of the hypothesis that the rate of fall in glucose concentration triggers counterregulatory hormonal responses in man. Diabetes 26:445-452.

[35] de Heer, J., Rasmussen, C., Coy, D.H., Holst, J.J., 2008. Glucagon-like peptide-1, but not glucose-dependent insulinotropic peptide, inhibits glucagon secretion via somatostatin (receptor subtype 2) in the perfused rat pancreas. Diabetologia 51:2263-2270.

[36] De Marinis, Y.Z., Salehi, A., Ward, C.E., Zhang, Q., Abdulkader, F., Bengtsson, M., et al., 2010. GLP-1 inhibits and adrenaline stimulates glucagon release by differential modulation of $\mathrm{N}$ - and $\mathrm{L}$-type $\mathrm{Ca} 2+$ channel-dependent exocytosis. Cell Metabolism 11:543-553.

[37] Polidori, D., Sha, S., Mudaliar, S., Ciaraldi, T.P., Ghosh, A., Vaccaro, N., et al., 2013. Canagliflozin lowers postprandial glucose and insulin by delaying intestinal glucose absorption in addition to increasing urinary glucose excretion: results of a randomized, placebo-controlled study. Diabetes Care 36:21542161.

[38] Hira, T., Koga, T., Sasaki, K., Hara, H., 2017. Canagliflozin potentiates GLP-1 secretion and lowers the peak of GIP secretion in rats fed a high-fat highsucrose diet. Biochemical and Biophysical Research Communications 492: $161-165$.

[39] Muhlemann, M., Zdzieblo, D., Friedrich, A., Berger, C., Otto, C., Walles, H., et al., 2018. Altered pancreatic islet morphology and function in SGLT1 knockout mice on a glucose-deficient, fat-enriched diet. Molecular Metabolism 13:67-76.

[40] Kadowaki, T., Inagaki, N., Kondo, K., Nishimura, K., Kaneko, G., Maruyama, N., et al., 2017. Efficacy and safety of canagliflozin as add-on therapy to 
teneligliptin in Japanese patients with type 2 diabetes mellitus: results of a 24week, randomized, double-blind, placebo-controlled trial. Diabetes Obesity and Metabolism 19:874-882.

[41] Stenlof, K., Cefalu, W.T., Kim, K.A., Alba, M., Usiskin, K., Tong, C., et al., 2013. Efficacy and safety of canagliflozin monotherapy in subjects with type 2 diabetes mellitus inadequately controlled with diet and exercise. Diabetes Obesity and Metabolism 15:372-382.

[42] Rosenstock, J., Aggarwal, N., Polidori, D., Zhao, Y., Arbit, D., Usiskin, K., et al., 2012. Dose-ranging effects of canagliflozin, a sodium-glucose cotransporter 2 inhibitor, as add-on to metformin in subjects with type 2 diabetes. Diabetes Care 35:1232-1238.

[43] Ferrannini, E., Ramos, S.J., Salsali, A., Tang, W., List, J.F., 2010. Dapagliflozin monotherapy in type 2 diabetic patients with inadequate glycemic control by diet and exercise: a randomized, double-blind, placebo-controlled, phase 3 trial. Diabetes Care 33:2217-2224.

[44] Bailey, C.J., Gross, J.L., Pieters, A., Bastien, A., List, J.F., 2010. Effect of dapagliflozin in patients with type 2 diabetes who have inadequate glycaemic control with metformin: a randomised, double-blind, placebo-controlled trial. Lancet 375:2223-2233.

[45] Scafoglio, C., Hirayama, B.A., Kepe, V., Liu, J., Ghezzi, C., Satyamurthy, N., et al., 2015. Functional expression of sodium-glucose transporters in cancer.
Proceedings of the National Academy of Sciences of the United States of America 112:E4111-E4119.

[46] Saito, T., Okada, S., Yamada, E., Shimoda, Y., Osaki, A., Tagaya, Y., et al., 2015. Effect of dapagliflozin on colon cancer cell [Rapid Communication]. Endocrine Journal 62:1133-1137.

[47] Sumida, Y., Seko, Y., Yoneda, M., 2017. Novel antidiabetic medications for non-alcoholic fatty liver disease with type 2 diabetes mellitus. Hepatology Research 47:266-280.

[48] Hartl, W.H., Demmelmair, H., Jauch, K.W., Koletzko, B., Schildberg, F.W., 1998. Effect of glucagon on protein synthesis in human rectal cancer in situ. Annals of Surgery 227:390-397.

[49] Kobori, O., Vuillot, M.T., Martin, F., 1982. Growth responses of rat stomach cancer cells to gastro-entero-pancreatic hormones. International Journal of Cancer 30:65-67.

[50] Moyer, M.P., Aust, J.B., Dixon, P.S., Levine, B.A., Sirinek, K.R., 1985 Glucagon enhances growth of cultured human colorectal cancer cells in vitro. Americas Journal of Surgery 150:676-679.

[51] Junker, A.E., Gluud, L., Holst, J.J., Knop, F.K., Vilsboll, T., 2016. Diabetic and nondiabetic patients with nonalcoholic fatty liver disease have an impaired incretin effect and fasting hyperglucagonaemia. Journal of Internal Medicine 279:485-493. 